\title{
Gigantic mysticete predators roamed the Eocene Southern Ocean
}

\author{
FELIX G. MARX 『1,2,3, MÓNICA R. BUONO4, ALISTAIR R. EVANS ${ }^{2,3}$, R. EWAN FORDYCE ${ }^{5,6}$, \\ MARCELO REGUERO ${ }^{7}$ and DAVID P. HOCKING 2,3 \\ ${ }^{1}$ Directorate Earth and History of Life, Royal Belgian Institute of Natural Sciences, \\ Brussels, Belgium \\ ${ }^{2}$ School of Biological Sciences, Monash University, Clayton, VIC., Australia \\ ${ }^{3}$ Geosciences, Museums Victoria, Melbourne, VIC., Australia \\ ${ }^{4}$ Instituto Patagónico de Geología y Paleontología (IPGP, CCT CONICET-CENPAT), Puerto Madryn, \\ Chubut, Argentina \\ ${ }^{5}$ Department of Geology, University of Otago, Dunedin, New Zealand \\ ${ }^{6}$ Departments of Vertebrate Zoology and Paleobiology, National Museum of Natural History, Smithsonian Institution, \\ Washington, DC, USA \\ ${ }^{7}$ Instituto Antártico Argentino (Dirección Nacional del Antártico), San Martín, Argentina \\ felix.marx@monash.edu
}

\begin{abstract}
Modern baleen whales (Mysticeti), the largest animals on Earth, arose from small ancestors around 36.4 million years ago (Ma). True gigantism is thought to have arisen late in mysticete history, with species exceeding $10 \mathrm{~m}$ unknown prior to $8 \mathrm{Ma}$. This view is challenged by new fossils from Seymour Island (Isla Marambio), Antarctica, which suggest that enormous whales once roamed the Southern Ocean during the Late Eocene (c. $34 \mathrm{Ma}$ ). The new material hints at an unknown species of the archaic mysticete Llanocetus with a total body length of up to $12 \mathrm{~m}$. The latter is comparable to that of extant Omura's whales (Balaenoptera omurai Wada et al. 2003), and suggests that gigantism has been a re-occurring feature of mysticetes since their very origin. Functional analysis including sharpness and dental wear implies an at least partly raptorial feeding strategy, starkly contrasting with the filtering habit of living whales. The new material markedly expands the size range of archaic mysticetes, and demonstrates that whales achieved considerable disparity shortly after their origin.
\end{abstract}

Received 2 July 2018, accepted 26 November 2018

Key words: Antarctica, baleen whale, Llanocetus, Palaeogene, raptorial, suction feeding

\section{Introduction}

Baleen whales are the largest animals on Earth, thanks to their ability to filter small prey from seawater using baleen (Pivorunas 1979, Werth 2000). In contrast to their living relatives, ancient mysticetes were relatively small: at a total body length of 3-4 m, archaic toothed species were diminutive (Fitzgerald 2010, Marx et al. 2015, Lambert et al. 2017), and even their baleen-bearing descendants generally stayed below $6 \mathrm{~m}$ until the Late Miocene (Slater et al. 2017). The single exception to this pattern is Llanocetus denticrenatus Mitchell 1989 from the latest Eocene of Antarctica, which is estimated to have reached a length of $8 \mathrm{~m}$ as early as $34 \mathrm{Ma}$ - possibly, as a result of its Southern Ocean habitat (Fordyce \& Marx 2018). The present paper shows that $L$. denticrenatus was neither exceptional, nor the largest of its kind. Three isolated premolar teeth from the Eocene of Antarctica, now housed at the Instituto Antártico Argentino and the Museo de La Plata (Argentina), hint at the existence of a second, substantially larger species of Llanocetus rivalling living baleen whales in size. Together with $L$. denticrenatus, this new material suggests at least two independent origins of gigantism in mysticete history, and reveals considerable size disparity arising from an early phase of morphological experimentation.

\section{Material and methods \\ Anatomical descriptions and body size}

Dental terminology follows Marx et al. (2015), with each tooth considered to have a main denticle (md) flanked by anterior $(\mathrm{ad})$ and posterior ( $\mathrm{pd}$ ) accessory denticles. Denticles are numbered away from md. In the absence of cranial remains, body size was estimated by comparing the size of the upper third premolar with the bizygomatic width of the skull across a variety of archaeocetes and archaic mysticetes. Total body length was then calculated based on bizygomatic width, using the equations of Pyenson \& Sponberg (2011) and Lambert et al. (2010).

\section{Tooth sharpness measurements}

The relative sharpness of the most complete tooth (IAA Pv731) was determined following the method of 
Hocking et al. (2017), which involves a series of individual sharpness measurements of the main denticle and first interdenticular notch (Supplementary Table S1). This is then followed by principal component and discriminant function analyses, both of which compare the new specimen to other archaic mysticetes, archaeocetes, the extinct odontocete Squalodon, and a range of extant terrestrial carnivorans with known feeding strategies (raptorial vs filter feeding).

The tooth was surface scanned using a Go!Scan 20 (Creaform Inc., Canada) with a point spacing of 0.1 $\mathrm{mm}$, and the resulting data assembled into a high resolution 3D model (.ply file format) in Meshlab (Istituto di Scienza e Tecnologie dell'Informazione "A. Faedo" and Consiglio Nazionale delle Ricerche, Italy). Minor cracks in the first posterior interdenticular notch were reconstructed in Geomagic Wrap (Geomagic Inc., North Carolina, USA), using the "curvature" setting of the fill-holes function, which provides a reconstruction based on the curvature of the surrounding undamaged surface mesh. Reconstructions were conservative and underestimate actual sharpness.

\section{Institutional abbreviations}

IAA, Instituto Antártico Argentino, San Martín, Argentina; MLP, Museo de La Plata, La Plata, Argentina; OU, Geology Museum, University of Otago, Dunedin, New Zealand; USNM, National Museum of Natural History, Smithsonian Institution, Washington DC, USA.

\section{Results}

Systematic palaeontology

Cetacea Brisson, 1762

Mysticeti Gray, 1864

Llanocetidae Mitchell, 1989

Llanocetus Mitchell, 1989

Type species. Llanocetus denticrenatus Mitchell, 1989

Emended diagnosis. Large-sized llanocetid sharing with other members of the family the presence of elongated nasals, low, elongate premolar crowns bearing strong labial and lingual enamel ornaments, and a broad sagittal trough on the parietals lacking a distinct sagittal crest. Differs from Mystacodon in its larger size, and from OU GS10897 in having apically curved accessory denticles and an abruptly depressed anterior entocingulum on the upper premolars.

\section{Llanocetus sp.}

Referred material. One complete upper third premolar (IAA Pv731) and two fragmentary lower premolars (MLP 12-XI-1-10a,b).
Locality and horizon. The new specimens were recovered from the Submeseta Formation of Seymour Island, Antarctic Peninsula. The La Meseta Formation was originally divided into seven stratigraphic levels, TELMs 1-7 (= Tertiary Eocene La Meseta of Sadler (1988)), ranging from the upper Ypresian (Early Eocene) to the late Priabonian (Late Eocene). Subsequently, the unit was redefined into the Submeseta and the La Meseta formations (Montes et al. 2013).

The highly fossiliferous sediments of the $c .230 \mathrm{~m}$ thick Submeseta Formation represent the uppermost part of the infill of the James Ross Basin, a back-arc basin developed on the eastern flank of the Antarctic Peninsula (Del Valle et al. 2004, Marenssi 2006). This formation comprises mostly poorly consolidated clastic fine-grained sediments, which were deposited in deltaic, estuarine and shallow marine environments (Marenssi et al. 1998). The Submeseta Formation is characterized by a uniform sandy lithology representing a storm-influenced tidal shelf. It includes three allomembers: Submeseta I (equivalent to TELMs 6 and 7 in partem), Submeseta II (equivalent to TELM 7 in partem), and Submeseta III (equivalent to upper TELM 7). MLP 12-XI-1-10 was recovered from Submeseta II (level 38 of Montes et al. 2013), while IAA Pv731 came from the Submeseta III (level 39 of Montes et al. 2013).

Magnetostratigraphically calibrated dinocyst biostratigraphy suggests a latest Eocene age (Priabonian) for middle and upper TELM 7 (Douglas et al. 2014), consistent with a mollusc-based ${ }^{87} \mathrm{Sr} /{ }^{86} \mathrm{Sr}$ date of $34.2 \pm$ $0.87 \mathrm{Ma}$ for the top of the same unit (Fordyce 2003).

Remarks. The new specimens closely match the archaic mysticete Llanocetus denticrenatus in having low, elongate, palmate crowns with apically curved accessory denticles; an abruptly depressed anterior portion of the entocingulum; strong, elongate to anastomosing enamel ridges both lingually and labially; completely unfused roots, with a broad interradicular space invading the base of the crown; and, especially on the nearly complete upper tooth, well-developed ecto- and entocingula (Fig. 1a \& b). They consistently differ from $L$. denticrenatus in their much larger size (maximum length of P3: 65 vs $42 \mathrm{~mm}$ ) and greater number of accessory denticles, with four posterior denticles on P3 and six posterior denticles on $\mathrm{p} 4$ of Llanocetus $\mathrm{sp}$. being matched by just three and five denticles in $L$. denticrenatus.

\section{Description}

IAA Pv731 (Fig. 1b \& c; Table I) is nearly complete, and here interpreted as a left P3 based on the presence of a moderately developed protocone remnant and the marked lingual curvature of the crown in anterior or posterior view. The crown consists of a main denticle flanked by 

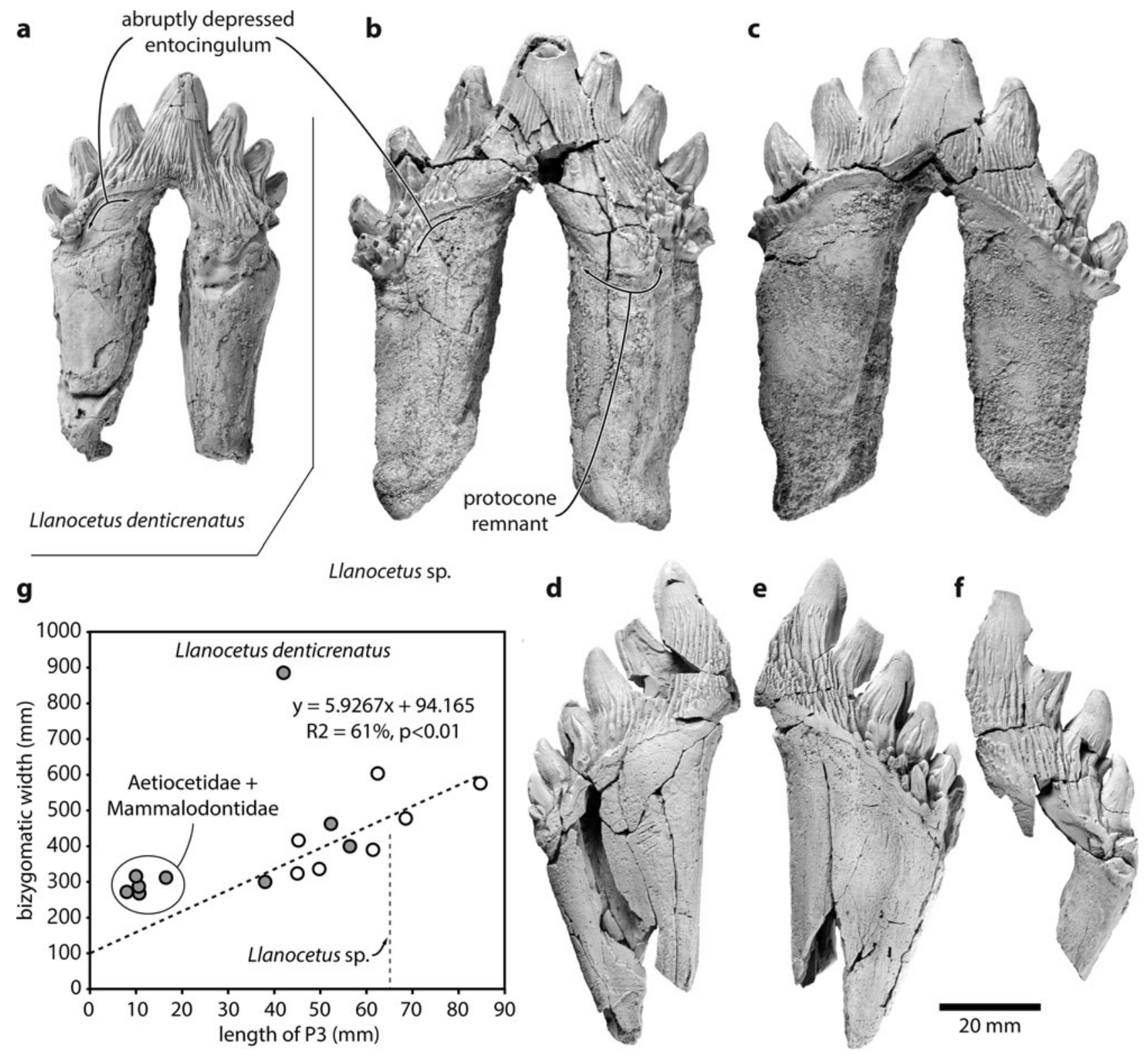

Fig. 1. Teeth of the large Eocene whale Llanocetus sp., and relationship between body and tooth size. Comparison of the left P3 of a. Llanocetus denticrenatus (USNM 183022) and Llanocetus sp. (IAA Pv731) in a., b. lingual and c. labial view; presumed right p4 (MLP 12-XI-1-10a) of Llanocetus sp. in d. labial and e. lingual view; f. left lower premolar (MLP 12-XI-1-10b) of Llanocetus sp. in labial view; g. length of P3 plotted against bizygomatic width (as a proxy for body length); empty circles represent basilosaurids, filled circles archaic mysticetes; the regression line is based on basilosaurids, Coronodon, Mystacodon, and OU GS10897.

three anterior and four posterior denticles, with pd 4 inferred from the presence of a large fracture surface posterior to pd3. The roots are robust, elongate, and markedly curved inwards. The posterior root bears well-defined longitudinal troughs both anteriorly and posteriorly. Both the ecto- and the entocingula are well developed, with a generally nodular rim and large cingular denticles on both sides of ad 2 and ad3, as well as lingual to pd4.

Enamel ornament on both sides of the crown consists of dorsoventral ridges rising from the cingulum on to each denticle. On ad3 in particular, the ridges are tall and sharp. Especially lingually, but also labial to ad2 and pd3, some of these ridges give rise to a series of denticles near the crown base. All of the major denticles bear anterior and posterior carinae. There is moderate apical abrasion forming windows in the enamel on ad1-pd2 (Fig. 2b). A similar degree of abrasion also seems to occur on three of the anterior cingular denticles, but fracturing of the enamel in this case prevents a clear assessment. As in the P3 of Llanocetus denticrenatus, there is no sign of attrition.

MLP 12-XI-1-10a (Fig. 1d \& e), here tentatively interpreted as a right $\mathrm{p} 4$ based on its size, slender crown, 
Table I. Measurements (in $\mathrm{mm}$ ) of Llanocetus sp.

\begin{tabular}{ll}
\hline IAA Pv731 - left P3 & $99+$ \\
Total height (crown + roots) & 65 \\
Length of crown at base & $51+$ \\
Height of crown, from anterior crown base to apex of main & \\
denticle & 26 \\
Maximum anteroposterior diameter of anterior root & 19 \\
Maximum transverse diameter of anterior root & 26 \\
Maximum anteroposterior diameter of posterior root & 27 \\
Maximum transverse diameter of posterior root & \\
MLP 12-XI-1-10a - (presumed) right p4 & $96+$ \\
Total height (crown + roots) & 34 \\
Maximum anteroposterior diameter of posterior root & 20 \\
Maximum transverse diameter of posterior root & \\
MLP 12-XI-1-10b - left lower premolar & $77+$ \\
Total height (crown + roots) & \\
\hline
\end{tabular}

and presence of labial attrition, consists of the posterior half of a tooth bearing six accessory denticles. The root is robust, straight in anterior view, and subdivided into two halves by a longitudinal trough running along its anterior surface. There is no protocone remnant. The ecto-and entocingula are indistinct near the centre of the crown, but extremely well developed posteriorly. As on P3, the enamel ornament consists of sharp, dorsoventrally oriented ridges rising from the cingulum on to the accessory denticles. Lingual to pd3-pd5, denticles arising from some of these ridges merge with cingular denticles to form a 'forest' covering the entire surface of the crown. Apical abrasion is present but mild, with no windows in the enamel. The labial surfaces of pd6 and the posteriormost cingular denticle bear small attritional facets.

MLP 12-XI-1-10b (Fig. 1f) is the least complete specimen, preserving only a partial root and the labial side of a fragmentary crown. The tooth is here interpreted as a left lower premolar based on its size and slender crown. There at least four denticles (uncertainly including the main denticle), with the anterior two being badly damaged. Posteriorly, the base of the third denticle gives rise to a notably smaller secondary denticle that partly occludes the space between the third and fourth denticles. The entocingulum is well developed posteriorly, but indistinct along the centre of the crown. Apical abrasion of the two posterior denticles is mild, with no windows in the enamel. There is no obvious sign of attrition.

\section{Body size estimation}

Plotting tooth length against bizygomatic width for a sample of archaeocetes and archaic mysticetes reveals a relatively complex pattern (Fig. 1g). The width of the cranium increases linearly with the length of P3 in basilosaurid archaeocetes, Coronodon, Mystacodon and OU GS10897. By contrast, aetiocetids and mammalodontids have somewhat smaller teeth than expected for their size, probably reflecting incipient homodonty and the presence of variably sized diastemata. The picture is further complicated by Llanocetus denticrenatus, which forms an extreme outlier characterized by large body size yet small teeth. This pattern allows for two potential interpretations of the new Llanocetus specimens from Antarctica:

a) Llanocetus denticrenatus is an isolated case, and the new material represents a related species with both absolutely and relatively larger teeth, and little or no diastemata (e.g. Mystacodon). Assuming this species follows the basilosaurid pattern would result in an estimated bizygomatic width of approximately 47.9 $\mathrm{cm}$, and thus a total body length of 4.4-4.6 m.

b) The new Llanocetus specimens are morphologically close to L. denticrenatus, and thus share the peculiar anatomy of its feeding apparatus. This view is supported by the obvious similarity of the teeth (Fig. 1a \& b), the geographical proximity of the localities where Llanocetus sp. and $L$. denticrenatus were found (both Seymour Island, Antarctica), and the absence of the pronounced dental wear characteristic of Mystacodon. In the absence of further comparative data that could inform the relationship between tooth and body size in Llanocetus, the simplest and least assumption-laden estimate is provided by isometric scaling. The latter puts Llanocetus sp. at roughly 1.55 times the length of $L$. denticrenatus (crown length of $\mathrm{P} 3=65 \mathrm{~mm}$ vs $42 \mathrm{~mm}$ ), suggesting a total body length of up to $12 \mathrm{~m}$.

Pending the discovery of better-preserved specimens, this paper argues that Llanocetus sp. and $L$. denticrenatus are most parsimoniously interpreted as sharing similar overall morphologies, and thus also comparable body proportions.

\section{Tooth sharpness}

Significant damage to the tip of the main denticle of IAA Pv731 made it difficult to create an accurate reconstruction, requiring us to take the sagittal and transverse measurements of tip sharpness from the well-preserved third posterior denticle. Visual examination of the main denticle reveals similarly developed anterior and posterior carinae, and suggests a tip shape broadly comparable to that of Llanocetus denticrenatus.

Principal component analysis shows the teeth of Llanocetus sp. to be remarkably sharp. Specifically, the results group IAA Pv731 with Llanocetus denticrenatus, and place both well within the morphospace defined by extant raptorial feeding carnivorans, such as lions, pumas and most pinnipeds - see Hocking et al. (2017) for details. Discriminate function analysis corroborates this result by classifying Llanocetus sp. as a raptorial feeder, rather than as a filter feeder. 
a

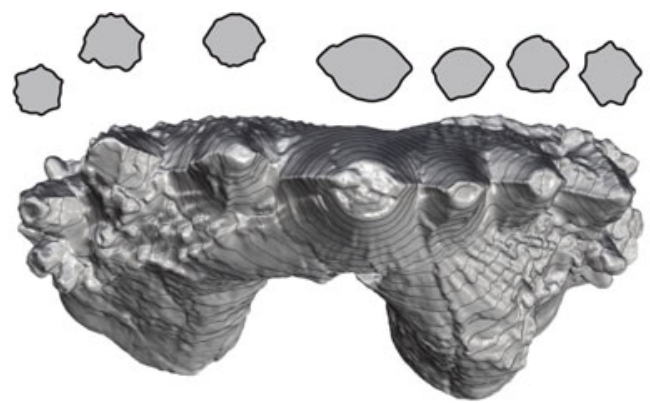

c
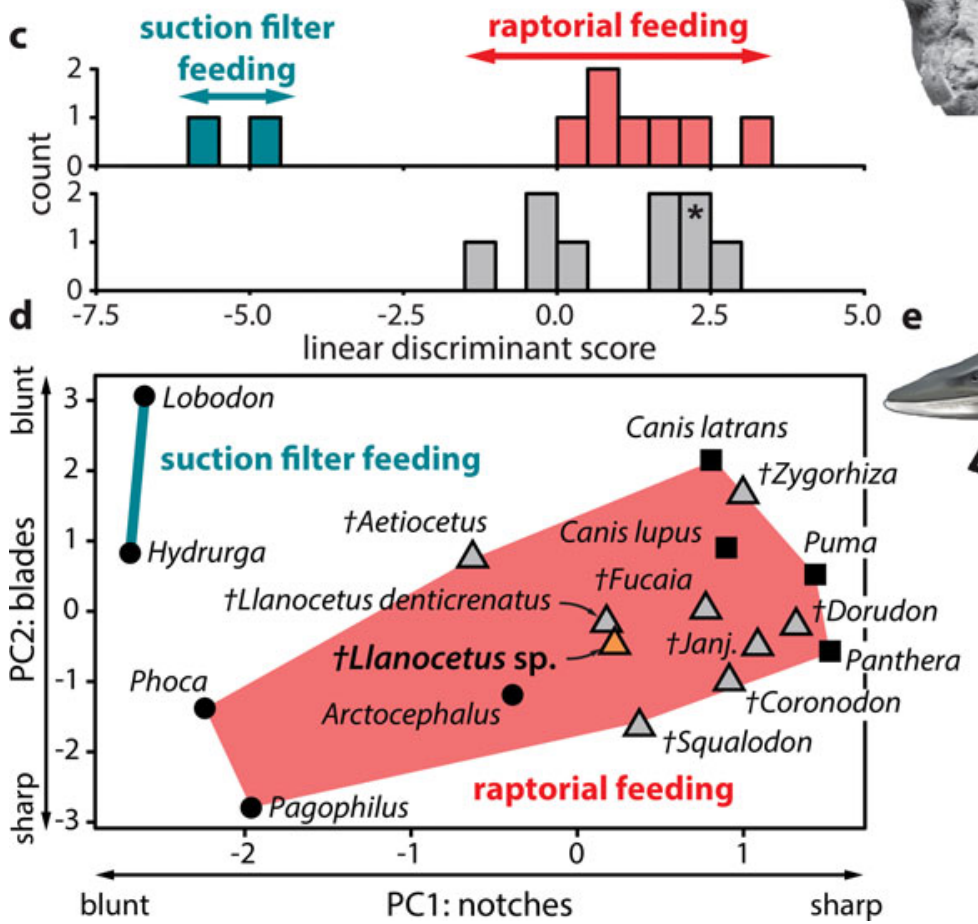

b shearing attrition

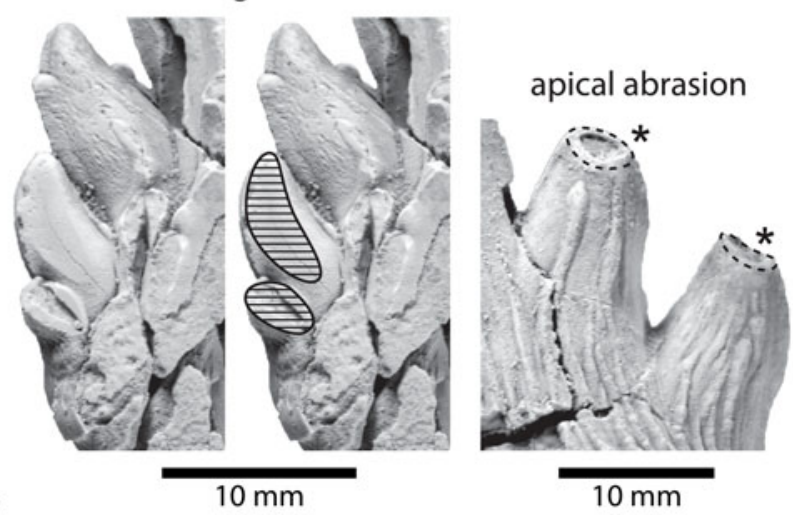

$10 \mathrm{~mm}$
$10 \mathrm{~mm}$

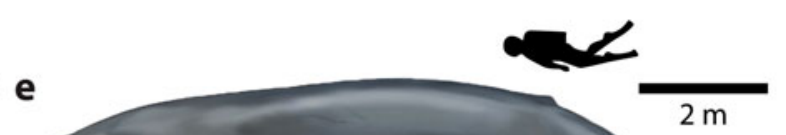

$2 \mathrm{~m}$

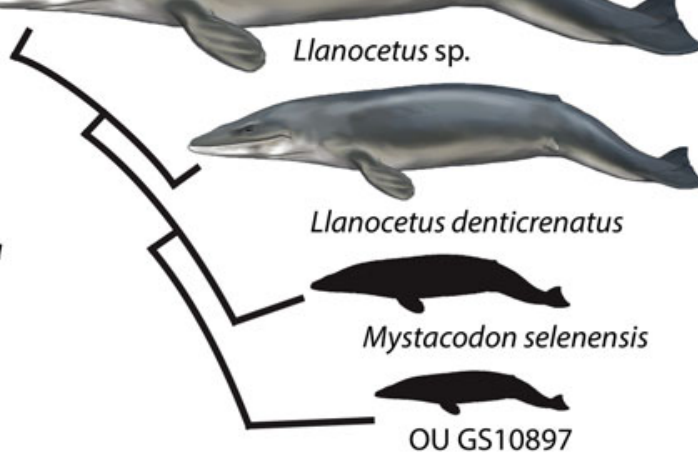

Fig. 2. Feeding strategy of Llanocetus sp. a. three-dimensional reconstruction of the left P3 of Llanocetus sp., with cross sections of the major denticles (at approximately $50 \%$ of their reconstructed heights); b. enlarged views of attritional (on MLP 12-XI-1-10a) and abrasive wear (on IAA Pv731); results of the c. discriminant function and d. principal component analyses of tooth sharpness in archaic mysticetes, based on the earlier analysis of Hocking et al. (2017); asterisk in c. marks the position of Llanocetus sp.; e. size disparity within Llanocetidae. Life reconstructions of whales by Carl Buell.

\section{Discussion}

At $12 \mathrm{~m}$, the estimated body length of Llanocetus sp. rivals that of living Bryde's and Omura's whales, and far exceeds that of any other archaic mysticete (Slater et al. 2017, Fordyce \& Marx 2018). Together, Llanocetus sp. and $L$. denticrenatus reveal an independent origin of gigantism early in mysticete evolution, predating the rise of large $(>10 \mathrm{~m})$ modern whales by roughly 25 million years (Tsai \& Kohno 2016, Slater et al. 2017, Fordyce \& Marx 2018).

The large size of Llanocetus may relate to its polar habitat, wide foraging area, or simply its feeding strategy. Large body size in whales is generally thought to be facilitated by their filter feeding habit (Werth 2000), especially in the context of a Pliocene shift towards dense but patchily distributed prey aggregations (Goldbogen \& Madsen 2018).
Llanocetus is an exception, with the morphology and wear of its teeth instead hinting at (suction-assisted) raptorial feeding (Fordyce \& Marx 2018). The new material corroborates this idea, with apical abrasion on the major denticles suggesting biting and direct tooth-on-food contact. In addition, incipient attrition on one of the lower teeth implies an occluding posterior dentition capable of slicing and processing prey (Fig. 2b).

Well-developed carinae traverse the anterior and posterior faces of each denticle, creating bladed edges that probably would cut food as it was forced into the interdenticular notches during jaw closure (Fig. 2a). As demonstrated by principal component and discriminant function analyses of functional shape characteristics, such a morphology is consistent with extant terrestrial carnivorans and piscivorous pinnipeds, but absent in tooth-assisted filter feeding seals like Hydrurga and 
Lobodon (Hocking et al. 2017) (Fig. 2c \& d). It is therefore inferred that Llanocetus sp., like its close relative $L$. denticrenatus, fed mostly raptorially.

Our new fossils firmly establish Llanocetus as one of the largest predators of its time. The size of its skull, as judged from a bizygomatic width of $886 \mathrm{~mm}$ in $L$. denticrenatus (Fordyce \& Marx 2018), and an isometrically scaled width of $1,370 \mathrm{~mm}$ in Llanocetus sp., far exceeded that of the largest contemporary archaeocetes, including Cynthiacetus (478 mm) (Martínez Cáceres et al. 2017) and Basilosaurus (576-622 mm) (Kellogg 1936). The sparseness of available material unfortunately prevents insights into likely prey types, although observations on extant killer whales suggest that moderate apical abrasion is more consistent with a diet of teleost fish than sharks (Ford et al. 2011). This interpretation assumes, of course, that moderate abrasion in this case does not simply reflect a relatively young individual.

Llanocetus sp. belongs to the still poorly understood, archaic mysticete family Llanocetidae, which also includes L. denticrenatus, Mystacodon, and an undescribed specimen from New Zealand (OU GS10897) (Fordyce \& Marx 2018; but see Lambert et al. 2017 for a different interpretation). A previous analysis partially diagnosed this clade based on the presence of a sagittal trough formed by the parietals (Fordyce \& Marx 2018). This diagnosis requires clarification, as a parietal trough also occurs in certain basilosaurids, such as Cynthiacetus and Dorudon. In the latter, however, the trough is narrow and cleft-like, as opposed to the more open, broader depression in llanocetids.

Additional features distinguishing the family are its greatly elongated nasals (Fordyce \& Marx 2018); low, elongate premolar crowns, contrasting with the much higher, more triangular premolars of basilosaurids, mammalodontids and aetiocetids (Emlong 1966, Barnes et al. 1995, Fitzgerald 2006, 2010, Marx et al. 2015, Peredo \& Pyenson 2018); strong lingual and labial enamel ornaments (shared with mammalodontids) (Fitzgerald 2010); and the absence of a sagittal crest on the parietals, a feature shared with Mammalodon and, to varying degrees, aetiocetids, but not Coronodon, Janjucetus, eomysticetids and basilosaurids (Deméré \& Berta 2008, Fitzgerald 2010, Snively et al. 2015, Boessenecker \& Fordyce 2016, Geisler et al. 2017).

The lack of a sagittal crest in llanocetids is especially noteworthy, since it implies a weaker (superficial) temporal muscle (see Carpenter \& White 1986). Along with the relatively flat rostrum and widely spaced teeth of $L$. denticrenatus, this may suggest that llanocetids had a less powerful bite than other archaic cetacean raptorial feeders, such as basilosaurids (Snively et al. 2015, Fordyce \& Marx 2018). To compensate, prey capture and/or transport may have been facilitated by other means, such as suction (Lambert et al. 2017).
Despite - or perhaps because of - their early origin, llanocetids are notably disparate in terms of their inferred body size and, presumably, feeding style (Fig. 2e). Unlike Llanocetus, Mystacodon only reaches about $4 \mathrm{~m}$, and is characterized by relatively closely spaced teeth with crowns obliterated by wear (Lambert et al. 2017). At about $3 \mathrm{~m}$, as inferred from its bizygomatic width (Lambert et al. 2010, Pyenson \& Sponberg 2011), OU GS10897 is just one quarter of the length of Llanocetus sp., yet has robust teeth bearing attritional shear facets. Such pronounced intrafamilial disparity is consistent with comparable variation in mammalodontids (macroraptorial vs suction feeding) (Fitzgerald 2010) and aetiocetids (variable degree of homodonty, suction vs raptorial feeding, wide range of body sizes) (Marx et al. 2015, Tsai \& Ando 2015, Marx et al. 2016), and supports previous suggestions of a phase of morphological and behavioural 'experimentation' early in mysticete evolution (Marx \& Fordyce 2015).

\section{Acknowledgements}

Thanks are due to the Instituto Antártico Argentino and Fuerza Aérea Argentina for logistical support, Guillermo López and Sergio Santillana who found the specimens studied here, Juan Jose Moly and Santiago Bessone for the preparation of the specimens, Pablo Navarro and Erich M.G. Fitzgerald for help with data acquisition, Carl Buell for providing life reconstructions of Llanocetus, and Alberto Collareta and Olivier Lambert for their constructive reviews. F.G.M. was funded by an EU Marie Skłodowska-Curie Global Postdoctoral fellowship (656010/ MYSTICETI), and M.R. by the Instituto Antártico Argentino (PICTA and PICTO 2010-0093).

\section{Author contribution}

F.G.M and M.R.B. conceived and organised the project. D.P.H. and A.R.E. carried out the tooth sharpness analyses. F.G.M., M.R.B. and R.E.F. contributed data and conducted the morphological analysis. M.R. coordinated the collection and study of the material. All authors discussed and wrote the paper.

\section{Supplemental Material}

Supplemental Table S1 can be found at http://doi.org/10. 1017/S095410201800055X

\section{References}

Barnes, L.G., Kimura, M., Furusawa, H. \& Samamura, H. 1995. Classification and distribution of Oligocene Aetiocetidae (Mammalia; Cetacea; Mysticeti) from western North America and Japan. Island Arc, 3, 10.1111/j.1440-1738.1994.tb00122.x. 
Boessenecker, R.W. \& Fordyce, R.E. 2016. A new eomysticetid from the Oligocene Kokoamu Greensand of New Zealand and a review of the Eomysticetidae (Mammalia, Cetacea). Journal of Systematic Palaeontology, 15, 10.1080/14772019.2016.1191045.

CARpenter, K. \& White, D. 1986. Feeding in the archaeocete whale Zygorhiza kochii (Cetacea: Archaeoceti). Mississippi Geology, 7, 1-14.

Del Valle, R.A., Elliot, D.H. \& Macdonald, D.I.M. 2004. Sedimentary basins on the east flank of the Antarctic Peninsula: proposed nomenclature. Antarctic Science, 4, 10.1017/ S0954102092000695.

Deméré, T.A. \& Berta, A. 2008. Skull anatomy of the Oligocene toothed mysticete Aetioceus weltoni (Mammalia; Cetacea): Implications for mysticete evolution and functional anatomy. Zoological Journal of the Linnean Society, 154, 10.1111/j.1096-3642.2008.00414.x.

Douglas, P.M.J., Affek, H.P., Ivany, L.C., Houben, A.J.P., SiJP, W.P., SLuis, A., et al. 2014. Pronounced zonal heterogeneity in Eocene southern high-latitude sea surface temperatures. Proceedings of the National Academy of Sciences, 111, 10.1073/pnas.1321441111.

EmLONG, D. 1966. A new archaic cetacean from the Oligocene of Northwest Oregon. Bulletin of the Museum of Natural History, University of Oregon, 3, 1-51.

FitzGerald, E.M.G. 2006. A bizarre new toothed mysticete (Cetacea) from Australia and the early evolution of baleen whales. Proceedings of the Royal Society, B273, 10.1098/rspb.2006.3664.

FitzGerald, E.M.G. 2010. The morphology and systematics of Mammalodon colliveri (Cetacea: Mysticeti), a toothed mysticete from the Oligocene of Australia. Zoological Journal of the Linnean Society, 158, 10.1111/j.1096-3642.2009.00572.x.

Ford, J.K.B., Ellis, G.M., Matkin, C.O., WetKlo, M.H., Barrett-Lennard, L.G. \& Withler, R.E. 2011. Shark predation and tooth wear in a population of northeastern Pacific killer whales. Aquatic Biology, 11, 10.3354/ab00307.

FordyCE, R.E. 2003. Cetacean evolution and Eocene-Oligocene oceans revisited. In Prothero, D.R., Ivany, L.C. \& Nesbitt, E.A., eds. From greenhouse to icehouse - the marine Eocene-Oligocene transition. New York: Columbia University Press, $541 \mathrm{pp}$.

FordyCE, R.E. \& MARX, F.G. 2018. Gigantism precedes filter feeding in baleen whale evolution. Current Biology, 28, 10.1016/ j.cub.2018.04.027.

Geisler, J.H., Boessenecker, R.W., Brown, M. \& Beatty, B.L. 2017. The origin of filter feeding in whales. Current Biology, 27, 10.1016/ j.cub.2017.06.003.

Goldbogen, J.A. \& Madsen, P.T. 2018. The evolution of foraging capacity and gigantism in cetaceans. The Journal of Experimental Biology, 221, 10.1242/jeb.166033.

Hocking, D.P., Marx, F.G., Fitzgerald, E.M.G. \& Evans, A.R. 2017. Ancient whales did not filter feed with their teeth. Biology Letters, 13, 10.1098/rsbl.2017.0348.

KellogG, R. 1936. A review of the Archaeoceti. Carnegie Institution of Washington Publication, 482, 1-366.

Lambert, O., Bianucci, G., Post, K., de Muizon, C., SalasGismondi, R., Urbina, M. \& Reumer, J. 2010. The giant bite of a new raptorial sperm whale from the Miocene epoch of Peru. Nature, 466, 10.1038/nature09067.

Lambert, O., Martínez-Cáceres, M., Bianucci, G., Di Celma, C., Salas-Gismondi, R., Steurbaut, E., et al. 2017. Earliest mysticete from the Late Eocene of Peru sheds new light on the origin of baleen whales. Current Biology, 27, 10.1016/j.cub.2017.04.026.
Marenssi, S.A., Santillana, S.N. \& Rinaldi, C.A. 1998. Stratigraphy of the La Meseta Formation (Eocene), Marambio (Seymour) Island, Antarctica. Asociación Paleontológica Argentina, Publicación Especial, 5, 137-146.

MARENSSI, S.A. 2006. Eustatically controlled sedimentation recorded by Eocene strata of the James Ross Basin, Antarctica. Geological Society, London, Special Publications, 258, 10.1144/gsl.sp.2006. 258.01.09.

Martínez Cáceres, M., Lambert, O. \& Muizon, C.D. 2017. The anatomy and phylogenetic affinities of Cynthiacetus peruvianus, a large Dorudon-like basilosaurid (Cetacea, Mammalia) from the late Eocene of Peru. Geodiversitas, 39, 7-163.

MARX, F.G. \& FordYCE, R.E. 2015. Baleen boom and bust: a synthesis of mysticete phylogeny, diversity and disparity. Royal Society Open Science, 2, 140434.

MarX, F.G., Tsai, C.-H. \& Fordyce, R.E. 2015. A new Early Oligocene toothed "baleen" whale (Mysticeti: Aetiocetidae) from western North America - one of the oldest and the smallest. Royal Society Open Science, 2, 10.1098/rsos.150476.

Marx, F.G., Hocking, D.P., Park, T., Ziegler, T., Evans, A.R. \& FitzGerald, E.M.G. 2016. Suction feeding preceded filtering in baleen whale evolution. Memoirs of Museum Victoria, 75, 10.24199/ j.mmv.2016.75.04.

Montes, M., Nozal, F., Santillana, S., Marenssi, S. \& Olivero, E. 2013. Mapa Geológico de la isla Marambio (Seymour) Escala 1:20.000 Primera Edición. Serie Cartográfica Geocientifica Antártica. Madrid/ Buenos Aires: Instituto Geológico y Minero de España and Instituto Antártico Argentino.

Peredo, C.M. \& Pyenson, N.D. 2018. Salishicetus meadi, a new aetiocetid from the late Oligocene of Washington State and implications for feeding transitions in early mysticete evolution. Royal Society Open Science, 5, 10.1098/rsos. 172336.

Pivorunas, A. 1979. The feeding mechanisms of baleen whales. American Scientist, 67, 432-440.

Pyenson, N.D. \& Sponberg, S.N. 2011. Reconstructing body size in extinct crown Cetacea (Neoceti) using allometry, phylogenetic methods and tests from the fossil record. Journal of Mammalian Evolution, 18, 10.1007/s10914-011-9170-1.

SADLER, P.M. 1988. Geometry and stratification of uppermost Cretaceous and Paleogene units on Seymour Island, northern Antarctic Peninsula. Geological Society of America Memoir, 169, 303-320.

Slater, G.J., Goldbogen, J.A. \& Pyenson, N.D. 2017. Independent evolution of baleen whale gigantism linked to Plio-Pleistocene ocean dynamics. Proceedings of the Royal Society B: Biological Sciences, 284, 10.1098/rspb.2017.0546.

Snively, E., FAhlKe, J.M. \& Welsh, R.C. 2015. Bone-breaking bite force of Basilosaurus isis (Mammalia, Cetacea) from the Late Eocene of Egypt estimated by finite element analysis. PLOS ONE, 10, 10.1371/ journal.pone. 0118380 .

TsaI, C.-H. \& ANDO, T. 2015. Niche partitioning in Oligocene toothed mysticetes (Mysticeti: Aetiocetidae). Journal of Mammalian Evolution, 23, 33-41.

TsaI, C.-H. \& Kohno, N. 2016. Multiple origins of gigantism in stem baleen whales. The Science of Nature, 103, 10.1007/ s00114-016-1417-5.

Werth, A.J. 2000. Feeding in marine mammals. In SchwenK, K., ed. Feeding: form, function and evolution in Tetrapods. San Diego, CA: Academic Press, 487-526. 